\title{
Appendiceal Carcinoma pT4 TNM Finding v7
}

National Cancer Institute

\section{Source}

National Cancer Institute. Appendiceal Carcinoma pT4 TNM Finding v7. NCI Thesaurus. Code C89901.

Appendiceal carcinoma with tumor penetrating visceral peritoneum including mucinous peritoneal tumor within the right lower quadrant and/or directly invading other organs or structures. Direct invasion in T4 includes invasion of other segments of the colorectum by way of the serosa, e.g., invasion of ileum. Tumor that is adherent to other organs or structures grossly is classified cT 4b. However, if no tumor is present in the adhesion microscopically, the classification should be pT1-3 depending on the anatomical depth of wall invasion. (from AJCC 7th Ed.) 